Revue d'histoire de l'Amérique française

REYUE D.HISTOIRE DE L'AMÉRIQUE FRANÇAISE

MORTON, Desmond et Glenn WRIGHT, Winning the Second

Battle: Canadian Veterans and the Return to Civilian Life

1915-1930. Toronto, University of Toronto Press, 1987. 17,95 \$

\title{
Carman Miller
}

Volume 42, numéro 2, automne 1988

URI : https://id.erudit.org/iderudit/304696ar

DOI : https://doi.org/10.7202/304696ar

Aller au sommaire du numéro

Éditeur(s)

Institut d'histoire de l'Amérique française

\section{ISSN}

0035-2357 (imprimé)

1492-1383 (numérique)

Découvrir la revue

Citer ce compte rendu

Miller, C. (1988). Compte rendu de [MORTON, Desmond et Glenn WRIGHT,

Winning the Second Battle: Canadian Veterans and the Return to Civilian Life

1915-1930. Toronto, University of Toronto Press, 1987. 17,95 \$]. Revue d'histoire

de l'Amérique française, 42(2), 295-296. https://doi.org/10.7202/304696ar d'utilisation que vous pouvez consulter en ligne.

https://apropos.erudit.org/fr/usagers/politique-dutilisation/ 
MORTON, Desmond and Glenn WRIGHT, Winning the Second Battle: Canadian Veterans and the Return to Civilian Life 1915-1930. Toronto, University of Toronto Press, 1987. 17,95\$

Winning the Second Battle traite de la démobilisation des 650000 vétérans canadiens de la Première Guerre mondiale, une tâche qui mit à l'épreuve l'ingéniosité et les ressources physiques du pays, mais qui s'avéra une précieuse leçon dans le domaine de l'administration publique de la sécurité sociale. Pour faciliter la transition des soldats démobilisés vers la vie civile, durant et immédiatement après la guerre, le Canada créa un ensemble de programmes incluant l'embauche préférentielle, les pensions, les assurances, les cours de formation, la réhabilitation, les soins hospitaliers ainsi qu'un plan pour l'établissement des soldats. Bien que les administrateurs canadiens de ces programmes s'inspirèrent largement de l'expérience des Français, des Britanniques et des Américains, ils construisirent finalement un système unique qui, à plusieurs égards, était supérieur à ceux de leurs alliés, un système que Morton et Wright désignent comme «le berceau de l'État-providence du Canada de l'aprèsguerre». Tout cela, cependant, ne s'est pas réalisé sans des luttes, des déceptions, des erreurs et des échecs; encore moins fut-il le fruit d'un pur idéalisme. Cette réalisation fut plutôt une réponse pragmatique aux pressions sociales, politiques et économiques.

Peu après la première bataille de la division canadienne à Ypres, en avril 1915, et avant le retour de ses nombreux blessés, le gouvernement canadien établissait une Commission hospitalière militaire, pour la prise en charge des malades et des invalides. Constituée surtout d'hommes d'affaires, et sous la présidence du sénateur James Lougheed, la Commission sembla davantage préoccupée de protéger le trésor public que de dispenser de l'aide aux volontaires de guerre. Avant toute chose, ils étaient déterminés à ne pas imiter le système de «pension de malheur» des Américains, héritage dispendieux et corrompu de la Guerre civile, tout comme ils voulaient s'éloigner de l'approche charitable, mais inefficace et conflictuelle, des Britanniques envers leurs invalides et leurs démobilisés. La Commission et son successeur, le ministère responsable du retour à la vie civile des soldats, élaborèrent plutôt des programmes pour que les vétérans se réinstallent comme membres autonomes et productifs de la société au lieu de demeurer un fardeau permanent pour la conscience publique. Pour faire avancer leurs demandes, les bénéficiaires s'engagèrent dans une deuxième bataille parallèle, par le biais d'une variété d'organisations de vétérans, représentant diverses régions et suggérant des programmes parfois divergents. La «Great War Veterans' Association» était le plus important de ces regroupements. De cette deuxième bataille où se 
mêlèrent les demandes contradictoires de la part des soldats, les rivalités interministérielles, les conflits de personnalités, les pressions politiques et les disputes judiciaires, émergea un programme fort cohérent et relativement généreux de ré-insertion à la vie civile. Ce programme administré par l'État, a valu au Canada la réputation gonflée de «pays où les vétérans se sentent entre amis». Tout cela a été réalisé dans une période de ressources limitées, de contrôle fiscal et d'opposition grandissante à un gouvernement trop envahissant. C'est ainsi par une redéfinition de la notion de «droits sociaux», que les vétérans gagnèrent cette deuxième bataille, sinon entièrement pour eux-mêmes, du moins pour leurs successeurs militaires et civils.

Les auteurs n'ignorent pas un aspect moins réussi de la démobilisation. Ainsi, ils racontent de manière détaillée l'impatience, les frustrations et la déception qui devaient mener, outre-mer, aux émeutes de Kinmel, Bramshott, Witley et Nivelles. Ils décrivent aussi les attaques cruelles et illégales des vétérans à l'égard des personnes et des propriétés de certains Canadiens qu'ils considéraient comme des ennemis étrangers. De plus, ils montrent comment les vétérans contribuèrent à alimenter la xénophobie dans la vie politique canadienne de l'entre-deux-guerres.

Bien que les auteurs présentent leur étude comme «rien de plus qu'une préface», ce livre constitue une description bien documentée et bien écrite de l'intégration des vétérans canadiens de la Première Guerre mondiale à la vie civile, un compte rendu qui permet de connaitre davantage une période de l'histoire canadienne relativement inexplorée. L'ouvrage contient aussi une excellente bibliographie, un index ainsi que des photographies et des tableaux statistiques. Cependant, le choix - que les auteurs n'ont pas justifié - de l'année 1930 comme date limite semble quelque peu déroutant, d'autant plus que l'étude s'étend jusqu'à la création de la Commission d'assistance aux anciens combattants en 1936. Ajoutons un point mineur: E. M. Macdonald, le député libéral de Pictou aux Communes et ministre de la Défense (1923-1926), n'aurait pas été heureux de se voir décrire comme un «libéral du Cap Breton». Néanmoins, ces petits défauts techniques enlèvent peu à cette étude de haut niveau.

Département d'histoire

Université McGill

CARMAN MILLER

Traduction: Philippe Benoit 